\title{
Both $\mathrm{NaCl}$ and $\mathrm{H}_{2} \mathrm{O}_{2}$ Long-Term
} Stresses Affect Basal Cytosolic $\mathrm{Ca}^{2+}$ Levels but Only $\mathrm{NaCl}$ Alters Cytosolic $\mathrm{Ca}^{2+}$ Signatures in Arabidopsis

\begin{abstract}
Lulu Liu',2t, Zhonghao Jiang ${ }^{3+}$, Shu Zhang ${ }^{1,2}$, Hongyan Zhao ${ }^{2}$, Weiguang Yang ${ }^{2,4}$, James N. Siedow ${ }^{3}$ and Zhen-Ming Pei, ${ }^{1,2,3 *}$

${ }^{1}$ College of Life Sciences, Zhejiang University, Hangzhou, China, ${ }^{2}$ Center on Plant Environmental Sensing, College of Life and Environmental Sciences, Hangzhou Normal University, Hangzhou, China, ${ }^{3}$ Department of Biology, Duke University, Durham, NC, United States, ${ }^{4}$ School of Life Sciences, Zhejiang Sci-Tech University, Hangzhou, China
\end{abstract}

Salinity is one of the formidable environmental factors that affect plant growth and development and constrain agricultural productivity. Experimentally imposed shortterm $\mathrm{NaCl}$ treatment triggers a transient increase in cytosolic free $\mathrm{Ca}^{2+}$ concentration $\left(\left[\mathrm{Ca}^{2+}\right]_{\mathrm{i}}\right)$ via $\mathrm{Ca}^{2+}$ influx across the plasma membrane. Salinity stress, as well as other stresses, induces the production of reactive oxygen species (ROS), such as $\mathrm{H}_{2} \mathrm{O}_{2}$. It is well established that short-term $\mathrm{H}_{2} \mathrm{O}_{2}$ treatment also triggers a transient increase in $\left[\mathrm{Ca}^{2+}\right]_{\mathrm{i}}$. However, whether and how long-term $\mathrm{NaCl}$ and $\mathrm{H}_{2} \mathrm{O}_{2}$ treatments affect the basal levels of $\left[\mathrm{Ca}^{2+}\right]_{i}$ as well as plant responses to additional $\mathrm{NaCl}$ and $\mathrm{H}_{2} \mathrm{O}_{2}$ stresses remain poorly understood. Using an aequorin-based $\mathrm{Ca}^{2+}$ imaging assay, we found that the long-term treatment of Arabidopsis seedlings with both moderate $\mathrm{NaCl}$ and $\mathrm{H}_{2} \mathrm{O}_{2}$ in the growth media reduced the basal $\left[\mathrm{Ca}^{2+}\right]_{i}$ levels. Interestingly, we found that the longterm treatment with $\mathrm{NaCl}$, but not $\mathrm{H}_{2} \mathrm{O}_{2}$, affected the responses of plants to additional $\mathrm{NaCl}$ stress, and remarkably the roots displayed enhanced responses while the leaves showed reduced responses. These findings suggest that plants adapt to the long-term $\mathrm{NaCl}$ stress, while $\mathrm{H}_{2} \mathrm{O}_{2}$ might be an integrator of many stresses.

\footnotetext{
Keywords: Arabidopsis thaliana, calcium imaging, aequorin, calcium signaling, basal cytosolic $\mathrm{Ca}^{2+}$ level, salt stress, oxidative stress
}

\section{INTRODUCTION}

Soil salinization impacts nearly every aspect of plant growth and development and causes enormous agricultural production losses all over the world (Hasegawa et al., 2000; Zhu, 2002, 2016). High salinity not only leads to continuing loss of arable land but also decreases crop yields. High salinity affects almost a quarter to one-third of global agricultural land, especially in irrigated areas. Previous studies show that high salinity led us to lose about 10 million hectares of agricultural land per year (Zhu, 2001; Munns and Tester, 2008; Deinlein et al., 2014). An additional challenge that compounded these losses is that agriculture needs to provide enough food for a rapidly expanding population in the world and stave off large-scale food shortages (Schroeder et al., 2013). So, it is vital to understand how plants perceive and respond to salt stress.

Abbreviations: $\mathrm{AQ}$, aequorin; $\left[\mathrm{Ca}^{2+}\right]_{\mathrm{i}}$, cytosolic free $\mathrm{Ca}^{2+}$ concentration; $\mathrm{CaM}$, calmodulin; $\mathrm{CBL}$, calcineurin B-like; $\mathrm{CDPK}, \mathrm{Ca}^{2+}$-dependent protein kinase; $\mathrm{CML}$, calmodulin-like; $\mathrm{HpC}$, hydrogen peroxide $\left(\mathrm{H}_{2} \mathrm{O}_{2}\right)$-gated $\mathrm{Ca}^{2+}$ channels; $\mathrm{NaC}$, $\mathrm{NaCl}$-gated $\mathrm{Ca}^{2+}$ channels; ROS, reactive oxygen species. 
Researchers have conducted many studies to dissect molecular and genetic mechanisms of plants' response to salt $(\mathrm{NaCl})$ stress, in which Arabidopsis thaliana was widely used. Excess $\mathrm{NaCl}$ in plants causes hyperosmotic stress and cellular ion imbalances (Zhu, 2003; Munns and Tester, 2008). $\mathrm{NaCl}$ stress triggers a transient increase in cytosolic $\mathrm{Ca}^{2+}$ concentration $\left(\left[\mathrm{Ca}^{2+}\right]_{\mathrm{i}}\right)$ in plants, leading to transcriptional regulation, subsequent growth, as well as developmental responses (Knight et al., 1997; Tracy et al., 2008). Although the molecular nature of initial salt stress perception is unclear, it is highly speculated that this salt-triggered rapid rise in $\left[\mathrm{Ca}^{2+}\right]_{\mathrm{i}}$, which lasts about $2 \mathrm{~min}$, represents a sensory process in plants (Munns and Tester, 2008; Deinlein et al., 2014). This is in accordance with the notion that cytosolic $\mathrm{Ca}^{2+}$ is a versatile secondary messenger and a vital element in a complex signaling network responding to different abiotic and biotic stimuli, including salt stress (Knight and Knight, 2001; Ru et al., 2008; Dodd et al., 2010; Marti et al., 2013). Given that $\left[\mathrm{Ca}^{2+}\right]_{i}$ of plants rapidly increased within a few seconds of exposure to $\mathrm{NaCl}$, plant salt sensor is likely to be tightly coupled with $\mathrm{Ca}^{2+}$ channels.

In saline environments, salt stress also triggers other stresses such as osmotic, ionic, and oxidative stresses, and hence the growth of plants also commonly rely on their ability to cope with these stresses (Bose et al., 2015). Environmental stresses including salt stress trigger plants accumulating reactive oxygen species (ROS), and overproduction of ROS such as hydrogen peroxide $\left(\mathrm{H}_{2} \mathrm{O}_{2}\right)$ occurs after salt stress treatment (Vaidyanathan et al., 2003; Borsani et al., 2005; Valderrama et al., 2006; Leshem et al., 2007; Miller et al., 2010; Ben Rejeb et al., 2014). As estimated from previous studies, the time constant for salt-triggered increases in $\left[\mathrm{Ca}^{2+}\right]_{\mathrm{i}}$ is approximately $20 \mathrm{~s}$ and for salt-triggered ROS is $400 \mathrm{~s}$ (Knight et al., 1997; Leshem et al., 2007; Jiang et al., 2013; Cao et al., 2017). It seems the rapid rise in $\left[\mathrm{Ca}^{2+}\right]_{i}$ happens earlier than the elevation of ROS imposed by salinity. Considering ROS can also trigger increases in $\left[\mathrm{Ca}^{2+}\right]_{\mathrm{i}}$ (McAinsh et al., 1996; Pei et al., 2000; Leshem et al., 2007; McAinsh and Pittman, 2009; Ma and Berkowitz, 2011), it is possible that, in the signal transduction pathway of salt stress, ROS-triggered $\left[\mathrm{Ca}^{2+}\right]_{i}$ rise perhaps functions as a feed-forward mechanism. According to recent studies of systemically propagating $\mathrm{Ca}^{2+}$ and ROS waves in plants, a new cell-to-cell communication pathway coupling with electric signals may help us understand how plant cells transmit long-distance signals (Gilroy et al., 2014; Kurusu et al., 2015). It should be noted that we have also found that salt-induced ROS could not trigger a detectable increase in $\left[\mathrm{Ca}^{2+}\right]_{\mathrm{i}}$ under the imposed experimental conditions (Jiang et al., 2013). In plants, every specific $\left[\mathrm{Ca}^{2+}\right]_{i}$ signature is generated by the accurately manipulated activities of $\mathrm{Ca}^{2+}$ channels and transporters which are located in different tissues, organelles, and membranes. Cytosolic $\mathrm{Ca}^{2+}$ sensors include the calcineurin B-like (CBL) protein families, the $\mathrm{Ca}^{2+}$-dependent protein kinase (CDPK), the calmodulin (CaM), and the calmodulin-like (CML), which could monitor and decode the information loaded in $\left[\mathrm{Ca}^{2+}\right]_{\mathrm{i}}$ signatures, allowing plants to give a quick response and tightly adapt to the ever-changing environment (Harper and Harmon, 2005; Dodd et al., 2010; Zhu et al., 2013). Previously we analyzed that the relationship and interaction of the $\left[\mathrm{Ca}^{2+}\right]_{i}$ increases are induced by salt stress and ROS in a short-term regime and found that $\mathrm{NaCl}$-gated $\mathrm{Ca}^{2+}$ channels $(\mathrm{NaC})$ and hydrogen peroxide $\left(\mathrm{H}_{2} \mathrm{O}_{2}\right)$-gated $\mathrm{Ca}^{2+}$ channels $(\mathrm{HpC})$ are different (Jiang et al., 2013). However, whether the long-term treatment of $\mathrm{NaCl}$ and $\mathrm{H}_{2} \mathrm{O}_{2}$ on the basal $\left[\mathrm{Ca}^{2+}\right]_{i}$ are the same with plants responses to short-term stresses remains poorly understood.

In this research, we have systematically analyzed the basal $\left[\mathrm{Ca}^{2+}\right]_{\mathrm{i}}$ under various long-term saline and oxidative growth conditions, and the $\left[\mathrm{Ca}^{2+}\right]_{\mathrm{i}}$ signatures in response to short-term stresses under these growth regimes. These findings will not only enable us to better understand how plants perceive high salt and ROS signals but also establish assays for phenotyping potential Arabidopsis mutants with defects in $\mathrm{NaCl}$ - or $\mathrm{H}_{2} \mathrm{O}_{2}$ induced $\left[\mathrm{Ca}^{2+}\right]_{\mathrm{i}}$ increases aiming to identify these sensitive $\mathrm{Ca}^{2+}$ channels.

\section{MATERIALS AND METHODS}

\section{Plant Materials and Growth Conditions}

Arabidopsis thaliana ecotype Columbia-0 (Col-0) constitutively expressing intracellular aequorin (pMAQ2, a kind gift from Dr. M. Knight) under the control of the cauliflower mosaic virus 35 S promoter was used (Knight et al., 1997; Tang et al., 2007). Seeds were sterilized with 2.5\% PPM (Plant Preservative Mixture; Caisson Labs) at $4^{\circ} \mathrm{C}$ for 3 days. Arabidopsis plants were grown in $150 \mathrm{~mm} \times 15 \mathrm{~mm}$ round Petri dishes in growth room. The culture media contained $1 / 2$ Murashige and Skoog salts (MS; Sigma), $1.5 \%$ (w/v) sucrose (Sigma), and 0.8\% (w/v) agar (Becton Dickinson), which was adjusted to $\mathrm{pH} 6.0$ with $\mathrm{KOH}$. We kept the temperature of the environmental rooms at $22 \pm 2{ }^{\circ} \mathrm{C}$. The photo fluency rate of white light was $\sim 110 \mu \mathrm{mol} \mathrm{m}^{-2} \mathrm{~s}^{-1}$, and the photoperiods were $16 \mathrm{~h}$ light/ $8 \mathrm{~h}$ dark cycles. $\mathrm{NaCl}$ and $\mathrm{H}_{2} \mathrm{O}_{2}$ were added to the $1 / 2$ MS media for saline and oxidative environments, respectively.

\section{Aequorin Reconstitution and Measurement of $\left[\mathrm{Ca}^{2+}\right]_{i}$}

Arabidopsis thaliana plants expressing cytosolic apoaequorin were used for $\left[\mathrm{Ca}^{2+}\right]_{\mathrm{i}}$ measurements (Knight et al., 1991; Tang et al., 2007; Yuan et al., 2014). Seedlings were grown on $1 / 2$ MS medium for 9 days. Reconstitution of aequorin was conducted in vivo by spraying seedlings with $240 \mu \mathrm{L}$ of $10 \mu \mathrm{M}$ coelenterazine per Petri dish followed by incubation at $22^{\circ} \mathrm{C}$ in the dark for $8 \mathrm{~h}$. Treatments and aequorin luminescence imaging were conducted at room temperature using a ChemiPro HT system including a cryogenically cooled and back-illuminated CCD camera or a newer version Lumazone system (Pylon1300B; Princeton Instruments) equipped with the H-800 light-tight controlled environmental box (Bio-One Scientific Instrument), liquid nitrogen auto filler (Roper Scientific or Bio-One Scientific Instrument), camera controller, and computer-equipped WinView/32 software (Roper Scientific) as described previously (Tang et al., 2007; Yuan et al., 2014). The CCD camera has a $1300 \times 1340$ pixel resolution and is cooled to $-120^{\circ} \mathrm{C}$ by the cryogenic cooling system before image recording. 
For the basal $\left[\mathrm{Ca}^{2+}\right]_{\mathrm{i}}$ levels, aequorin luminescence $(\mathrm{L})$ record lasted $30 \mathrm{~min}$ in seedlings grown under different concentrations of $\mathrm{NaCl}$ or $\mathrm{H}_{2} \mathrm{O}_{2}$. For the changes in $\left[\mathrm{Ca}^{2+}\right]_{\mathrm{i}}$ levels in response to $\mathrm{NaCl}$ and $\mathrm{H}_{2} \mathrm{O}_{2}$ stresses, aequorin luminescence (L) were recorded starting $50 \mathrm{~s}$ prior to the treatments, and luminescence images were taken every $10 \mathrm{~s}$ as done in our previous research (Jiang et al., 2013). In the dark, the solutions (100 mL) of $\mathrm{H}_{2} \mathrm{O}_{2}$ or $\mathrm{NaCl}$ solution was added into the Petri dish, and aequorin bioluminescence was recorded continuously (Yuan et al., 2014). Seedlings were treated with a discharging solution containing $0.9 \mathrm{M} \mathrm{CaCl}_{2}$ in $10 \%(\mathrm{v} / \mathrm{v})$ ethanol and recorded for $5 \mathrm{~min}$ to estimate the total remaining aequorin bioluminescence $\left(\mathrm{L}_{\max }\right)$ (Knight et al., 1997; Rentel and Knight, 2004; Tang et al., 2007; Yuan et al., 2014). Finally, we used MetaMorph 7.7 to analyze the recorded image data. Considering that the relative $\left[\mathrm{Ca}^{2+}\right]_{\mathrm{i}}$ is relevant to the study, the $\left[\mathrm{Ca}^{2+}\right]_{\mathrm{i}}$ levels were shown as the ratio between aequorin luminescence $(\mathrm{L})$ and total remaining aequorin $\left(\mathrm{L}_{\text {max }}\right)$ as mentioned previously (Kiep et al., 2015; Ranf et al., 2015). All the experiments were conducted at room temperature, which was between 22 and $24^{\circ} \mathrm{C}$.

\section{Real-Time RT-PCR}

Seedlings were grown on normal $1 / 2$ MS media or $1 / 2$ MS media added with $40 \mathrm{mM} \mathrm{NaCl}$ or $1 \mathrm{mM} \mathrm{H}_{2} \mathrm{O}_{2}$, for 10 days. The RNAs of leaves and roots were extracted separately, $50 \mathrm{mg}$ sample of each, using RNA sample Total RNA Kit (TIANGEN). One microgram RNA was used for reverse transcription to generate the first strand of cDNA by FastKing RT Kit (TIANGEN). RTPCR reaction was carried out using RealUniversal Color PreMix (TIANGEN). Eight-well optical PCR plate was used for each RTPCR reaction, where each reaction contained $7.5 \mu \mathrm{L}$ Premix, $1.5 \mu \mathrm{L}$ forward primer, $1.5 \mu \mathrm{L}$ reverse primer, $1.5 \mu \mathrm{L}$ RNasefree $\mathrm{H}_{2} \mathrm{O}$, and $3 \mu \mathrm{L}$ cDNA template. The PCR cycle parameters were set as follows: 1 cycle of $15 \mathrm{~min}$ at $95^{\circ} \mathrm{C}$, and 40 cycles of $10 \mathrm{~s}$ at $95^{\circ} \mathrm{C}, 20 \mathrm{~s}$ at $60^{\circ} \mathrm{C}$, and $30 \mathrm{~s}$ at $72^{\circ} \mathrm{C}$. Tublin was used as an internal control to normalize the gene expression level. Primers used in this study are listed in Supplementary Table S1. A melting curve was made after 40 cycles were completed to make sure that only single amplified products were obtained. The standard $t$-test was used for the statistical analysis.

\section{RESULTS}

\section{Long-Term Salt and Oxidative Stresses Lower the Basal $\left[\mathrm{Ca}^{2+}\right]_{i}$}

Calcium plays fundamentally essential extracellular and intracellular roles and often serves as a life and death signal in animals and plants (Berridge et al., 2003; Hofer and Brown, 2003; Dodd et al., 2010). At the resting level, the basal $\left[\mathrm{Ca}^{2+}\right]_{\mathrm{i}}$ is tightly maintained at a concentration that is $\sim 20,000$-fold below the extracellular $\mathrm{Ca}^{2+}$ concentration (Berridge et al., 2003; Clapham, 2007; Swanson et al., 2011). Since a failure in the regulation of basal $\left[\mathrm{Ca}^{2+}\right]_{\mathrm{i}}$ leads to a vast array of severe diseases in humans, including cancers, neuron degeneration diseases, and cardiovascular diseases, the maintenance of adequate basal $\left[\mathrm{Ca}^{2+}\right]_{i}$ seems to be essential for all organisms (Roderick and Cook, 2008; Sammels et al., 2010). In plants, the basal $\left[\mathrm{Ca}^{2+}\right]_{\mathrm{i}}$ displays diurnal oscillation patterns (Johnson et al., 1995) and is regulated by soil $\mathrm{Ca}^{2+}$ levels (Tang et al., 2007). In the current study, we observed significant variations of the basal $\left[\mathrm{Ca}^{2+}\right]_{\mathrm{i}}$ levels in these seedlings, when we used $\mathrm{NaCl}$ media-grown seedlings of the ecotype Col-0 expressing cytosolic apoaequorin detective in stimulus-induced $\left[\mathrm{Ca}^{2+}\right]_{\mathrm{i}}$ increases, similar to the osmo-sensing mutant osca1, for aequorin-based $\mathrm{Ca}^{2+}$ imaging analyses, we observed remarkably significant variations of the basal $\left[\mathrm{Ca}^{2+}\right]_{\mathrm{i}}$ levels in these seedlings. This observation trigged us to ask a question regarding whether the long-term treatments of $\mathrm{NaCl}$ and $\mathrm{H}_{2} \mathrm{O}_{2}$ affect the basal $\left[\mathrm{Ca}^{2+}\right]_{\mathrm{i}}$, which is in line with our previous study on the $\left[\mathrm{Ca}^{2+}\right]_{\mathrm{i}}$ signatures with short-term salt and ROS stresses (Jiang et al., 2013).

We grew Arabidopsis seedlings expressing the $\mathrm{Ca}^{2+}$ indicator aequorin in the MS medium containing 0 to $80 \mathrm{mM} \mathrm{NaCl}$. It should be noted that the concentrations of $\mathrm{NaCl}$ were used with the consideration that the seedling growth should not be profoundly inhibited by $\mathrm{NaCl}$, and thus the aequorin measurement would not be significantly affected. In other words, the seedlings looked largely normal without the apparent growth and developmental phenotypes. Aequorin bioluminescence images were taken at $30 \mathrm{~min}$, and the relative value of luminescence $\left(\mathrm{L} / \mathrm{L}_{\max }\right)$ was calculated and analyzed for the basal $\left[\mathrm{Ca}^{2+}\right]_{\mathrm{i}}$ (Figure 1A). Surprisingly, we observed that the basal $\left[\mathrm{Ca}^{2+}\right]_{\mathrm{i}}$ was decreased in response to the long-term treatment of $\mathrm{NaCl}$ (Figure 1A), which was in contrast to the well-known phenomenon of transient increases in $\left[\mathrm{Ca}^{2+}\right]_{\mathrm{i}}$ upon the shortterm $\mathrm{NaCl}$ treatment. Plants grown on the MS medium without $\mathrm{NaCl}$ had a relative basal $\left[\mathrm{Ca}^{2+}\right]_{\mathrm{i}}\left(\mathrm{L} / \mathrm{L}_{\max }\right)$ of $3.72 \pm 0.24 \times 10^{-2}$ in the roots (Figure 1B). The basal $\left[\mathrm{Ca}^{2+}\right]_{\mathrm{i}}$ levels decreased under $\mathrm{NaCl}$ treatment in a concentration-dependent manner (Figure 1B), i.e., the higher the concentration of $\mathrm{NaCl}$ in the growth media the lower the basal $\left[\mathrm{Ca}^{2+}\right]_{\mathrm{i}}$. The basal $\left[\mathrm{Ca}^{2+}\right]_{\mathrm{i}}$ decreased to $1.75 \pm 0.33 \times 10^{-2}$ at $70 \mathrm{mM} \mathrm{NaCl}$ and maintained the similar value at $80 \mathrm{mM} \mathrm{NaCl}$ in the roots. We also noted that the reduction of basal $\left[\mathrm{Ca}^{2+}\right]_{i}$ in the roots was more than that in the leaves (Figure 1B). To figure out whether and how the changes in the basal $\left[\mathrm{Ca}^{2+}\right]_{\mathrm{i}}$ affect $\mathrm{NaCl}$ - or $\mathrm{H}_{2} \mathrm{O}_{2}$ triggered transient increases in $\left[\mathrm{Ca}^{2+}\right]_{i}$, we should identify an optimum concentration of $\mathrm{NaCl}$ in the growth media, as described previously, for potential up- and down-regulation. The ideal concentration should be used to produce about half of the maximum level of the basal $\left[\mathrm{Ca}^{2+}\right]_{\mathrm{i}}$ (Jiang et al., 2013). Figure 1B shows that the concentration of $\mathrm{NaCl}$ required for a half-maximal response was $\sim 40 \mathrm{mM}$, and hence we chose $40 \mathrm{mM} \mathrm{NaCl}$ for the subsequent experiments.

Besides, we researched the basal $\left[\mathrm{Ca}^{2+}\right]_{\mathrm{i}}$ levels in response to added $\mathrm{H}_{2} \mathrm{O}_{2}$ in the growth media. Seedlings were grown in MS medium with different concentrations of $\mathrm{H}_{2} \mathrm{O}_{2}$, which was from 0 to $2 \mathrm{mM}$. We also analyzed the basal $\left[\mathrm{Ca}^{2+}\right]_{\mathrm{i}}$ as described above for $\mathrm{NaCl}$. Interestingly, the long-term treatment of $\mathrm{H}_{2} \mathrm{O}_{2}$ also lowered the basal $\left[\mathrm{Ca}^{2+}\right]_{\mathrm{i}}$ levels in a dose-dependent manner (Figures 1C,D). Similarly, the basal $\left[\mathrm{Ca}^{2+}\right]_{\mathrm{i}}$ levels were more sensitive to $\mathrm{H}_{2} \mathrm{O}_{2}$ in the roots than in the leaves (Figure 1D). Finally, $1 \mathrm{mM} \mathrm{H}_{2} \mathrm{O}_{2}$ was chosen as the optimum concentration, in which the magnitude of $\left[\mathrm{Ca}^{2+}\right]_{\mathrm{i}}$ was similar to that in the media with $40 \mathrm{mM} \mathrm{NaCl}$. 

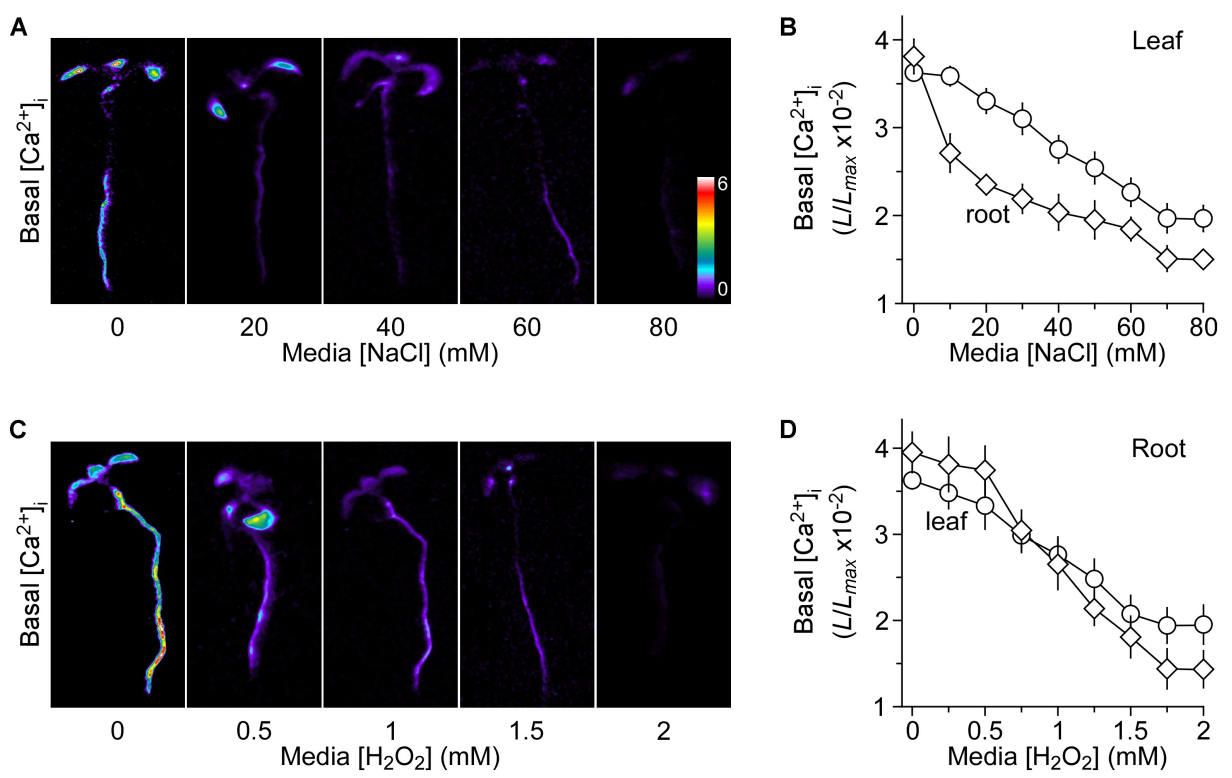

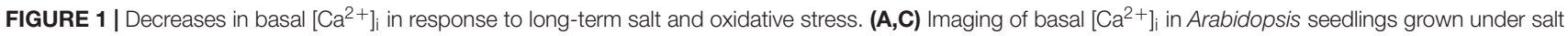
and oxidative stresses. Seedlings expressing aequorin were grown in the agar media containing several concentrations of $\mathrm{NaCl}(\mathrm{A})$ or $\mathrm{H}_{2} \mathrm{O}_{2}$ (C) for 9 days. $\mathrm{Basal}$ $\left[\mathrm{Ca}^{2+}\right]_{\mathrm{i}}$ in whole seedlings was analyzed by imaging aequorin luminescence $(\mathrm{L})$ for $30 \mathrm{~min}$. Relative $\left[\mathrm{Ca}^{2+}\right]_{\mathrm{i}}$ was shown as $\mathrm{L} / \mathrm{L}_{\mathrm{max}}\left(\times 10^{-2}\right)$, and scaled by a pseudo-color bar, where $L_{\max }$ is the total aequorin luminescence. (B,D) Quantification of basal $\left[\mathrm{Ca}^{2+}\right]_{i}$ in these seedlings grown under $\left.\mathrm{NaCl}_{\mathbf{B}} \mathbf{B}\right)$ and $\mathrm{H}_{2} \mathrm{O}_{2}$ (D) from experiments as shown in $(\mathbf{A}, \mathbf{C})$, respectively. The basal $\left[\mathrm{Ca}^{2+}\right]_{i}$ levels in leaves and roots were analyzed separately. The data from four independent experiments are shown (mean \pm SEM; $n=20$ ).

\section{Response on $\left[\mathrm{Ca}^{2+}\right]_{i}$ Induced by Short-Term Stimulus After Long-Term $\mathrm{NaCl}$ and $\mathrm{H}_{2} \mathrm{O}_{2}$ Pretreatment}

We then asked whether the long-term treatment of Arabidopsis with $\mathrm{NaCl}$ affects plants' response to short-term $\mathrm{NaCl}$ stress. In other words, we asked whether plants are sensitized or desensitized to $\mathrm{NaCl}$ stress when they grow in $\mathrm{NaCl}$ media. To determine $\mathrm{NaCl}$-induced $\left[\mathrm{Ca}^{2+}\right]_{\mathrm{i}}$ increases in Arabidopsis seedling grown under salt environments and to investigate these $\left[\mathrm{Ca}^{2+}\right]_{\mathrm{i}}$ increases in roots and leaves separately, we detected the temporal dynamics of $\mathrm{NaCl}$-induced $\left[\mathrm{Ca}^{2+}\right]_{\mathrm{i}}$ increases without $\mathrm{NaCl}$ in the grown media as controls for further comparison. After the application of $\mathrm{NaCl}$, the $\left[\mathrm{Ca}^{2+}\right]_{\mathrm{i}}$ elevated immediately, reached a peak at about $20 \mathrm{~s}$, and then declined gradually as described previously (Jiang et al., 2013). Several concentrations of $\mathrm{NaCl}$, ranging from 0 to $600 \mathrm{mM}$, were applied and the peak values of $\left[\mathrm{Ca}^{2+}\right]_{\mathrm{i}}$ were plotted as a function of the applied $\mathrm{NaCl}$ concentrations in the roots (Figure 2A) and leaves (Figure 2B), separately, for celerity. The magnitudes of $\left[\mathrm{Ca}^{2+}\right]_{\mathrm{i}}$ were increased with increases in the concentration of $\mathrm{NaCl}$ (Figures $2 \mathbf{A}, \mathbf{B}$ ). The magnitudes of $\mathrm{NaCl}$-induced $\left[\mathrm{Ca}^{2+}\right]_{i}$ increases were higher in the roots than in the leaves (Figure 2C), similar to those seen in a previous study (Tracy et al., 2008), while similar to another previous finding (Jiang et al., 2013), we found that half of the maximum amplitude $\left[\mathrm{Ca}^{2+}\right]_{\mathrm{i}}$ response was about $200 \mathrm{mM}$, both in the roots and leaves.

To access how the consistent presence of $\mathrm{NaCl}$ stress in the growth media affects the plants' response to additional $\mathrm{NaCl}$ stress, the seedlings that were grown in the $40 \mathrm{mM} \mathrm{NaCl}$ media were treated with gradient concentrations of $\mathrm{NaCl}$ from 0 to $600 \mathrm{mM}$. We found that the $\left[\mathrm{Ca}^{2+}\right]_{\mathrm{i}}$ increases in response to $\mathrm{NaCl}$ in $\mathrm{MS}$ medium containing $40 \mathrm{mM} \mathrm{NaCl}$ were qualitatively consistent with the response to $\mathrm{NaCl}$ in general $\mathrm{MS}$, and a higher $\mathrm{NaCl}$ induced a greater peak of $\left[\mathrm{Ca}^{2+}\right]_{\mathrm{i}}$ (Figures 2A,B). When changes in $\left[\mathrm{Ca}^{2+}\right]_{\mathrm{i}}$ were detectable in the leaf which was grown in MS containing $40 \mathrm{mM} \mathrm{NaCl}$, the increasing trend was smaller compared with those in MS. On the contrary, the changes in $\left[\mathrm{Ca}^{2+}\right]_{\mathrm{i}}$ that were detectable in the root which grew in salt environment were higher. The root was more sensitive than the leaf under the salt environment compared with the seedling grown in MS (Figure 2C).

Besides, to investigate thoroughly the relationship of $\mathrm{H}_{2} \mathrm{O}_{2}$ induced $\left[\mathrm{Ca}^{2+}\right]_{\mathrm{i}}$ increases in the root and leaf, the temporal dynamics of $\left[\mathrm{Ca}^{2+}\right]_{\mathrm{i}}$ increases triggered by $\mathrm{H}_{2} \mathrm{O}_{2}$ were further compared. Seedlings were stimulated by concentrations of $\mathrm{H}_{2} \mathrm{O}_{2}$ from 0 to $15 \mathrm{mM}$ in MS. After the application of $\mathrm{H}_{2} \mathrm{O}_{2}$, the $\left[\mathrm{Ca}^{2+}\right]_{\mathrm{i}}$ increased immediately and reached a peak at about $50 \mathrm{~s}$, and then declined gradually. As expected, $\mathrm{H}_{2} \mathrm{O}_{2}$ induced increases in $\left[\mathrm{Ca}^{2+}\right]_{\mathrm{i}}$ in a dose-dependent manner (Figures 2D,E). Current results were similar to those reported previously (Jiang et al., 2013). We found that $\left[\mathrm{Ca}^{2+}\right]_{\mathrm{i}}$ increased in response to $\mathrm{H}_{2} \mathrm{O}_{2}$ and the magnitudes of $\left[\mathrm{Ca}^{2+}\right]_{i}$ depended on the concentration of $\mathrm{H}_{2} \mathrm{O}_{2}$, the higher the concentration of $\mathrm{H}_{2} \mathrm{O}_{2}$ the higher the magnitude of $\left[\mathrm{Ca}^{2+}\right]_{\mathrm{i}}$ (Figures 2D,E). However, after the application of $\mathrm{H}_{2} \mathrm{O}_{2}$, the $\left[\mathrm{Ca}^{2+}\right]_{\mathrm{i}}$ increased immediately, and $\left[\mathrm{Ca}^{2+}\right]_{\mathrm{i}}$ increase in the root was similar to that in the leaf, which was different from the $\mathrm{NaCl}$-induced $\left[\mathrm{Ca}^{2+}\right]_{i}$ increases 

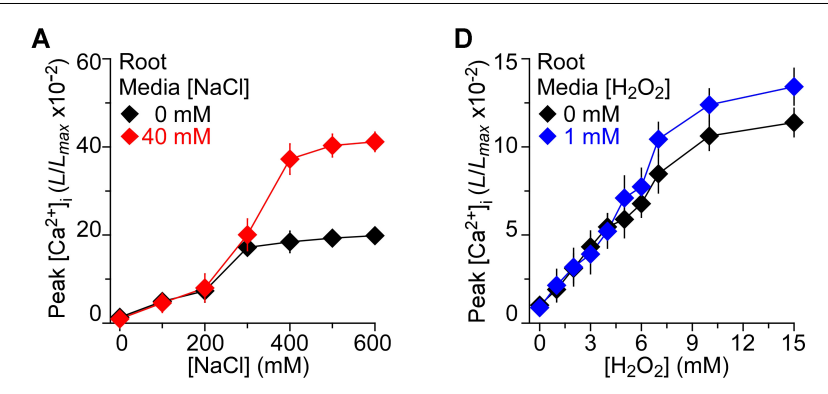

B

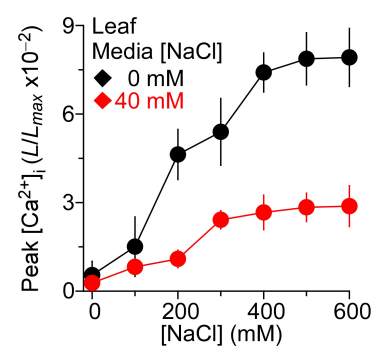

E

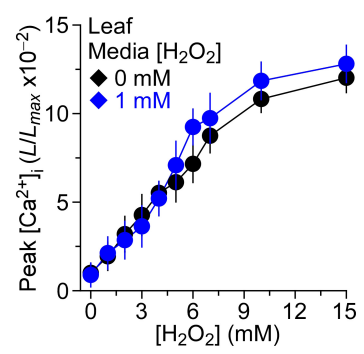

C

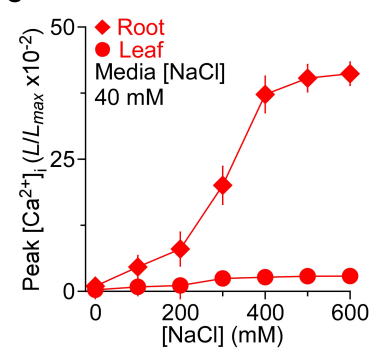

$\mathbf{F}$

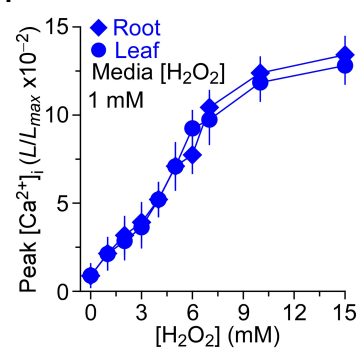

FIGURE 2 | The effects of $\mathrm{NaCl}$ and $\mathrm{H}_{2} \mathrm{O}_{2}$ growth environments on increases in $\left[\mathrm{Ca}^{2+}\right]_{i}$ induced by $\mathrm{NaCl}$ and $\mathrm{H}_{2} \mathrm{O}_{2}$, respectively. (A-C) Arabidopsis seedlings expressing aequorin grown under 0 or $40 \mathrm{mM} \mathrm{NaCl}$ for 9 days were treated with several concentrations of $\mathrm{NaCl}$, and aequorin luminescence images were taken every $10 \mathrm{~s}$, for $200 \mathrm{~s}$. Data are averaged peak values of increases in $\left[\mathrm{Ca}^{2+}\right]_{i}$ induced by $\mathrm{NaCl}$ in roots $(\mathbf{A})$ and leaves (B), respectively. The sensitivities of $\left[\mathrm{Ca}^{2+}\right]_{i}$ to $\mathrm{NaCl}$ in leaves and roots from seedlings grown under $40 \mathrm{mM} \mathrm{NaCl}$ are directly compared in (C). Data from four independent experiments are shown (mean $\pm \mathrm{SEM} ; n=20$ ). (D-F) Seedlings grown under 0 or $1 \mathrm{mM} \mathrm{H}_{2} \mathrm{O}_{2}$ for 9 days were treated with several concentrations of $\mathrm{H}_{2} \mathrm{O}_{2}$, and aequorin images were taken every $10 \mathrm{~s}$, for $200 \mathrm{~s}$. Data are averaged peak values of $\left[\mathrm{Ca}^{2+}\right]_{i}$ increases in roots (D) and leaves (E), respectively. The sensitivities of $\left[\mathrm{Ca}^{2+}\right]_{i}$ to $\mathrm{H}_{2} \mathrm{O}_{2}$ in leaves and roots grown under $1 \mathrm{mM} \mathrm{H}_{2} \mathrm{O}_{2}$ are directly compared in $(\mathbf{F})$. Data from four independent experiments are shown (mean \pm SEM; $n=20$ ).

(Figures 2D,E). To further study how the changes in $\mathrm{H}_{2} \mathrm{O}_{2}$ induced $\left[\mathrm{Ca}^{2+}\right]_{\mathrm{i}}$ increases in the oxidative environment, the seedlings were grown in MS medium containing $1 \mathrm{mM} \mathrm{H}_{2} \mathrm{O}_{2}$. We then found that the increases in $\left[\mathrm{Ca}^{2+}\right]_{\mathrm{i}}$ in response to $\mathrm{H}_{2} \mathrm{O}_{2}$ from 0 to $15 \mathrm{mM}$ in MS medium containing $1 \mathrm{mM} \mathrm{H}_{2} \mathrm{O}_{2}$ were qualitatively the same as those grown in the control MS media. The difference of $\left[\mathrm{Ca}^{2+}\right]_{i}$ between the root and leaf in the oxidative environment was a little higher than that in the general environment (Figures 2D,E). Additionally, the $\left[\mathrm{Ca}^{2+}\right]_{\mathrm{i}}$ increases induced by $\mathrm{H}_{2} \mathrm{O}_{2}(0-15 \mathrm{mM})$ in root were similar to these in leaf of seedlings grown in the oxidative environment (Figure 2F).

\section{Long-Term $\mathrm{NaCl}$ Treatment Alters Short-Term Response of $\left[\mathrm{Ca}^{2+}\right]_{i}$ to $\mathrm{NaCl}$ but $\mathrm{Not} \mathrm{H}_{2} \mathrm{O}_{2}$}

Previous studies have reported that the $\mathrm{NaCl}$ concentration for a half-maximal response was about $200 \mathrm{mM}$, and the magnitude of $\left[\mathrm{Ca}^{2+}\right]_{\mathrm{i}}$ was similar to that induced by $4 \mathrm{mM} \mathrm{H}_{2} \mathrm{O}_{2}$ (Jiang et al., 2013). The seedlings grown in MS as a control and responses to the stimulus measured using a ChemiPro system were also presented. To further study the changes in $\left[\mathrm{Ca}^{2+}\right]_{\mathrm{i}}$ induced by $\mathrm{NaCl}$ and $\mathrm{H}_{2} \mathrm{O}_{2}$ in salt environment, we applied $200 \mathrm{mM} \mathrm{NaCl}$ or $4 \mathrm{mM} \mathrm{H}_{2} \mathrm{O}_{2}$ to stimulate seedlings grown in MS medium and MS medium containing $40 \mathrm{mM} \mathrm{NaCl}$, respectively (Figure 3). The $\left[\mathrm{Ca}^{2+}\right]_{\mathrm{i}}$ increased immediately and reached the peak at approximately $50 \mathrm{~s}$, and then gradually declined. In the roots, the peak $\left[\mathrm{Ca}^{2+}\right]_{\mathrm{i}}$ reached $5.64 \pm 0.31\left(\times 10^{-2}\right)$ in MS medium, which was similar to the peak $\left[\mathrm{Ca}^{2+}\right]_{\mathrm{i}}$ in seedlings grown in salt medium $\left[5.31 \pm 0.20\left(\times 10^{-2}\right)\right]$ (Figure 3A). In the leaves, the peak value reached $5.52 \pm 0.22\left(\times 10^{-2}\right)$ in MS medium, which was similar to the root (Figure 3B). Nevertheless, the $\left[\mathrm{Ca}^{2+}\right]_{\mathrm{i}}$ increases were markedly declined in the leaf of the seedlings grown in salt medium (Figure 3C).

At the same time, we analyzed increases in $\left[\mathrm{Ca}^{2+}\right]_{\mathrm{i}}$ in response to $200 \mathrm{mM} \mathrm{NaCl}$ in seedlings grown in MS medium and MS medium containing $40 \mathrm{mM} \mathrm{NaCl}$. After the application of $200 \mathrm{mM} \mathrm{NaCl},\left[\mathrm{Ca}^{2+}\right]_{\mathrm{i}}$ was increased immediately, reached a peak at about $20 \mathrm{~s}$, and then declined gradually (Figures 3D,E). Interestingly, although in the root the peak $\left[\mathrm{Ca}^{2+}\right]_{\mathrm{i}}$ reached $7.32 \pm 0.35\left(\times 10^{-2}\right)$ in the MS medium control, which was similar to the peak $\left[\mathrm{Ca}^{2+}\right]_{\mathrm{i}}$ in the salt medium condition $\left[7.99 \pm 0.32\left(\times 10^{-2}\right)\right]$ (Figure 3D), the peak $\left[\mathrm{Ca}^{2+}\right]_{\mathrm{i}}$ was decreased significantly in the leaf under the salt medium condition compared with MS medium (Figures 3E,F). Also, we found that $\mathrm{NaCl}$-induced $\left[\mathrm{Ca}^{2+}\right]_{\mathrm{i}}$ increases in root reached $4.63 \pm 0.19\left(\times 10^{-2}\right)$, which was higher than that in leaf $\left[1.09 \pm 0.11\left(\times 10^{-2}\right)\right]$, although the $\left[\mathrm{Ca}^{2+}\right]_{\mathrm{i}}$ increases of whole seedlings were similar to those under $\mathrm{H}_{2} \mathrm{O}_{2}$ treatment.

\section{Long-Term $\mathrm{H}_{2} \mathrm{O}_{2}$ Treatment Does Not Alter $\mathrm{H}_{2} \mathrm{O}_{2}$ - or $\mathrm{NaCl}$-Induced $\left[\mathrm{Ca}^{2+}\right]_{i}$ Increases}

We wished to investigate further how the changes in $\left[\mathrm{Ca}^{2+}\right]_{i}$ were triggered by $\mathrm{NaCl}$ and $\mathrm{H}_{2} \mathrm{O}_{2}$ in the oxidative environment. For this, $4 \mathrm{mM} \mathrm{H}_{2} \mathrm{O}_{2}$ and $200 \mathrm{mM} \mathrm{NaCl}$ were applied to seedlings grown in MS medium and MS medium with $1 \mathrm{mM}$ $\mathrm{H}_{2} \mathrm{O}_{2}$, respectively (Figure 4). By analogy, we found that in the root, $4 \mathrm{mM} \mathrm{H} \mathrm{O}_{2}$ induced an immediate and rapid rise in the $\left[\mathrm{Ca}^{2+}\right]_{\mathrm{i}}$ which resulted in similar peaks at about $50 \mathrm{~s}$ under MS medium and $\mathrm{H}_{2} \mathrm{O}_{2}$ medium conditions, and then declined gradually (Figure 4A). We also found that the temporal dynamics of $\left[\mathrm{Ca}^{2+}\right]_{\mathrm{i}}$ increases was similar in both the root and the leaf (Figures $\mathbf{4 A - C}$ ). Equally we analyzed the changes in $\mathrm{NaCl}$-induced $\left[\mathrm{Ca}^{2+}\right]_{\mathrm{i}}$ increases in the oxidative environment. The $\left[\mathrm{Ca}^{2+}\right]_{\mathrm{i}}$ in response to $200 \mathrm{mM} \mathrm{NaCl}$ under MS medium and $\mathrm{MS}$ medium containing $1 \mathrm{mM} \mathrm{H}_{2} \mathrm{O}_{2}$ was examined. The $\left[\mathrm{Ca}^{2+}\right]_{\mathrm{i}}$ increased immediately in the root after being treated 


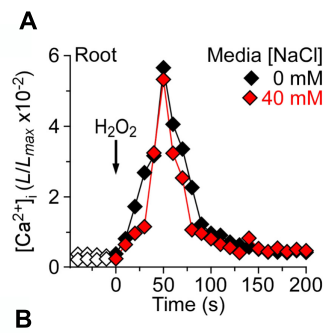

B
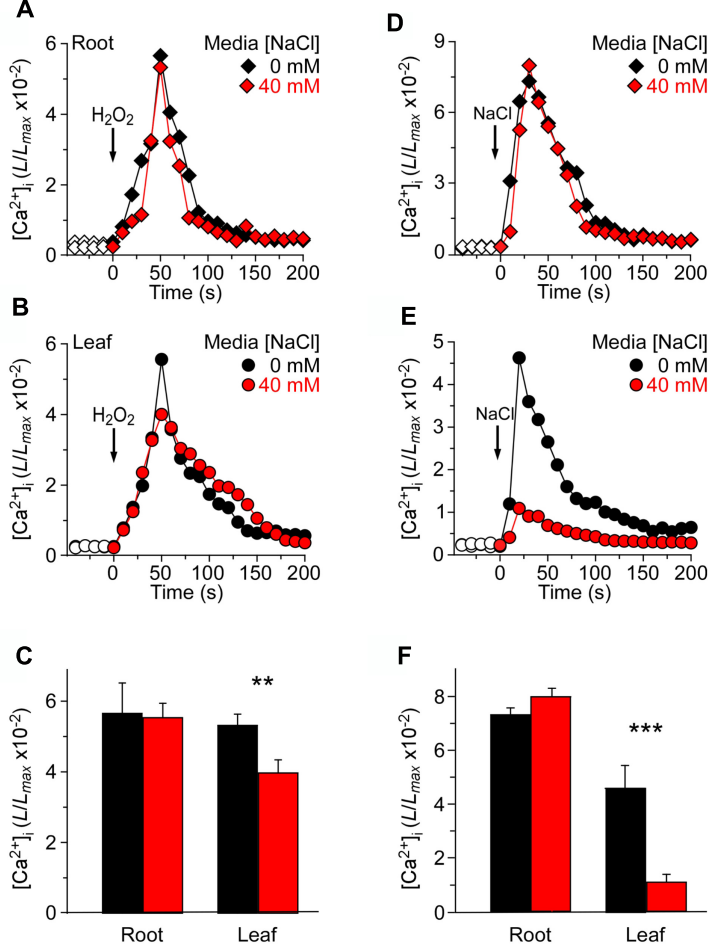

FIGURE 3 | Long-term treatment of seedlings by $\mathrm{NaCl}$ in the growth media affects $\left[\mathrm{Ca}^{2+}\right]_{i}$ increases induced by $\mathrm{NaCl}$ but not $\mathrm{H}_{2} \mathrm{O}_{2}$. (A-C) Arabidopsis seedlings grown in MS media containing 0 or $40 \mathrm{mM} \mathrm{NaCl}$ for 9 days were subjected to a $4 \mathrm{mM} \mathrm{H}_{2} \mathrm{O}_{2}$ treatment at $\mathrm{O} \mathrm{s}$, and aequorin luminescence images in roots $(\mathbf{A}, \mathbf{C})$ and leaves $(\mathbf{B}, \mathbf{C})$ were taken every $10 \mathrm{~s}$ throughout the treatment. Representative recordings from individual seedlings were shown. Similar results were seen in four independent experiments using 20 seedlings. (D-F) Similar seedlings as in (A,B) were treated with $200 \mathrm{mM} \mathrm{NaCl}$ at time zero, and aequorin images in roots $(\mathbf{D}, \mathbf{F})$ and leaves $\mathbf{( E , F )}$ were recorded continuously throughout the treatment. Representative recordings from individual seedlings were shown. Similar results were seen in four independent experiments using 20 seedlings (mean $\pm \mathrm{SD} ; n=20$; *** $P<0.001$; $* * 0.001<P<0.01)$.

with $200 \mathrm{mM} \mathrm{NaCl}$, and reached a peak of $7.32 \pm 0.33\left(\times 10^{-2}\right)$ in normal medium and $8.07 \pm 0.26\left(\times 10^{-2}\right)$ in $\mathrm{H}_{2} \mathrm{O}_{2}$ medium (Figure 4D). However, the $\left[\mathrm{Ca}^{2+}\right]_{\mathrm{i}}$ increases in the leaf were lower than that in the root. Additionally, after $200 \mathrm{mM} \mathrm{NaCl}$ treatment, the peak $\left[\mathrm{Ca}^{2+}\right]_{\mathrm{i}}$ that was increased in the $\mathrm{H}_{2} \mathrm{O}_{2}$ medium had a remarkable decline compared to that in MS medium (Figure 4F).

To further assess the reason why the root is more sensitive to $\mathrm{NaCl}$ but not $\mathrm{H}_{2} \mathrm{O}_{2}$, we measured the expression patterns of $\mathrm{Ca}^{2+}$ signal relative marker genes, such as SOS1, SOS2, SOS3, TPC1, ZAT12, and RBOHD in both the leaf and the root. For ROS stress marker genes, ZAT12, RBOHD, and TPC1, the ZAT12 and RBOHD were all up-regulated both in the leaf and the root, but the TPC1 relative expression was down-regulated in both the leaf and the root (Supplementary Figures S1A,B). It is known that TPC1 expelled $\mathrm{Ca}^{2+}$ from the vacuole to the cytosol in Arabidopsis thaliana, which contributed to long-distance $\mathrm{Ca}^{2+}$ signature (Evans et al., 2016; Guo et al., 2017). The expression of

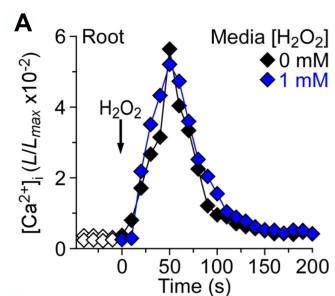

B

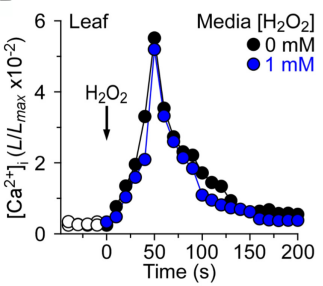

C

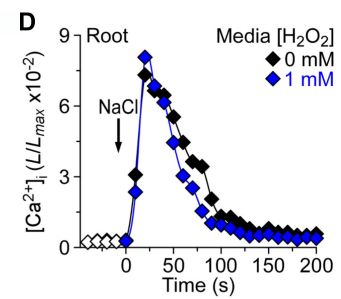

E

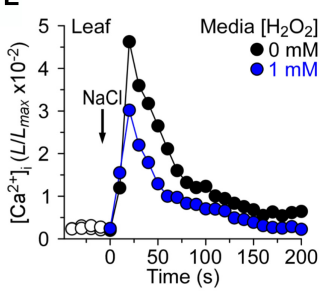

$\mathbf{F}$
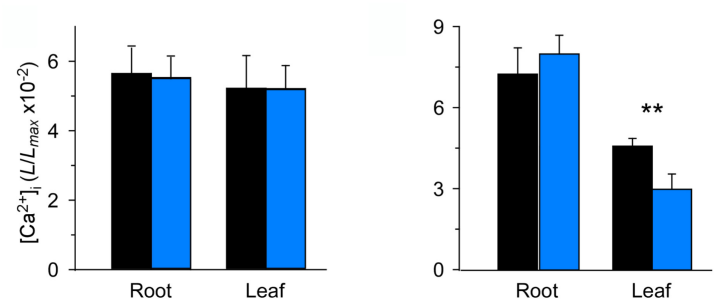

FIGURE 4 | Long-term treatment of plants by $\mathrm{H}_{2} \mathrm{O}_{2}$ in the growth media has negligible effects on $\left[\mathrm{Ca}^{2+}\right]_{i}$ increases induced by either $\mathrm{H}_{2} \mathrm{O}_{2}$ or $\mathrm{NaCl}$. (A-C) Arabidopsis seedlings grown in MS media containing 0 or $1 \mathrm{mM} \mathrm{H}_{2} \mathrm{O}_{2}$ for 9 days were subjected to a $4 \mathrm{mM} \mathrm{H}_{2} \mathrm{O}_{2}$ treatment at $0 \mathrm{~s}$, and aequorin luminescence images in roots $(\mathbf{A}, \mathbf{C})$ and leaves $\mathbf{( B , C )}$ were taken every $10 \mathrm{~s}$ throughout the treatment. Representative recordings from individual seedlings were shown. Similar results were seen in four independent experiments using 20 seedlings. (D-F) Similar seedlings as in (A,B) were treated with $200 \mathrm{mM}$ $\mathrm{NaCl}$ at time zero, and aequorin images in roots $\mathbf{( D , F )}$ and leaves $\mathbf{( E , F )}$ were recorded continuously throughout the treatment. Representative recordings from individual seedlings were shown. Similar results were seen in four independent experiments using 20 seedlings (mean \pm SD; $n=20$;

$* * 0.001<P<0.01)$.
TPC1 was down-regulated, thus $\mathrm{Ca}^{2+}$ released from the vacuole might be also decreased. This might lead to higher cytosolic basal $\mathrm{Ca}^{2+}$ levels, which is clearly not one of the reasons for lower cytosolic $\mathrm{Ca}^{2+}$ seen in Figure 1. Meanwhile, during long-term salt stress, the marker genes, such as SOS1, SOS2, and SOS3, were all up-regulated much more in the root compared to that in the leaf (Supplementary Figures S1C,D). For marker gene TPC1, the expression in the root was reduced, while it was increased in the leaf (Supplementary Figures S1C,D). The TPC1 expression levels may be associated with $\mathrm{Ca}^{2+}$ signaling rather than the basal $\mathrm{Ca}^{2+}$ levels, and more so in the leaf with respect to salt stress (Supplementary Figure S1).

\section{DISCUSSION}

Calcium is a critical second messenger in signal transduction in animals and plants (Berridge et al., 2003; Clapham, 2007; 
McAinsh and Pittman, 2009; Ward et al., 2009). Previous studies have shown that specific stimuli can trigger unique temporal and spatial patterns of $\left[\mathrm{Ca}^{2+}\right]_{i}$, known as " $\left[\mathrm{Ca}^{2+}\right]_{i}$ signatures," which are thought to function in most aspects of plant growth and development (Tang et al., 2007; Dodd et al., 2010; Jiang et al., 2013). Cytosolic $\mathrm{Ca}^{2+}$ concentrations can be monitored by imaging the $\mathrm{Ca}^{2+}$ indicator aequorin, and the intensity of bioluminescence only depends on the $\mathrm{Ca}^{2+}$ concentration. It is well-known that the basal $\left[\mathrm{Ca}^{2+}\right]_{\mathrm{i}}$ is maintained at $100 \mathrm{nM}$ and about 20,000-fold below the extracellular $\mathrm{Ca}^{2+}$ concentration (Epstein, 1961; Berridge et al., 2003; Hepler, 2005; Clapham, 2007; Swanson et al., 2011). Environmental stimuli activate the $\mathrm{Ca}^{2+}$ channels in general located at the plasma membrane and/or endomembranes, leading to the increases in $\left[\mathrm{Ca}^{2+}\right]_{\mathrm{i}}$ (Hetherington and Brownlee, 2004; Ward et al., 2009). The $\mathrm{Ca}^{2+}$ signature encodes information from the environmental stimuli and is then decoded by intracellular $\mathrm{Ca}^{2+}$ sensors, such as $\mathrm{CBL}$ proteins and calmodulins, which initiate the downstream events (Clapham, 2007; Zhu et al., 2013). Over the past decades, a significant progress has been made in understanding the changes in $\left[\mathrm{Ca}^{2+}\right]_{\mathrm{i}}$ that were induced by various abiotic and biotic stresses in plants, including the responses to salt stress, drought, oxidative stress, high and low temperatures, mechanical wounding, and pathogen elicitors (McAinsh and Pittman, 2009; Dodd et al., 2010; Ma and Berkowitz, 2011; Kaya et al., 2014; Yuan et al., 2014). In line with this, we have isolated a mutant with defects in osmotic stress-induced $\left[\mathrm{Ca}^{2+}\right]_{\mathrm{i}}$ increases and identified the osmosensor OSCA1 (Yuan et al., 2014). Interestingly, many abiotic and biotic stresses also induce the accumulation of ROS and generate oxidative stresses, which play an important role in many aspects of plant growth and development (Wise and Naylor, 1987; Mittler, 2002; Vranova et al., 2002; Suzuki et al., 2012; Kaya et al., 2014). For instance, it has been known that salt stress enhances the accumulation of ROS in plants, and hydrogen peroxide has been proposed to function in salt-triggered calcium wave propagations (Vaidyanathan et al., 2003; Borsani et al., 2005; Valderrama et al., 2006; Leshem et al., 2007; Miller et al., 2010; Choi et al., 2016).

It has long been hypothesized that salt stress-triggered increases in $\left[\mathrm{Ca}^{2+}\right]_{i}$ was involved in the perception of the salt signal, even though much remains to be discovered about the properties of the salt-activated $\mathrm{Ca}^{2+}$ permeable channel and its molecular nature (Zhu, 2001; Munns and Tester, 2008). Additionally, the molecular mechanisms of ROS sensing in plant cells are still unknown, and probably ROS activation of $\mathrm{Ca}^{2+}$ permeable channels may serve as an ROS perception process (Pei et al., 2000; Waring, 2005; Miller et al., 2010). Note that the rapid rise in $\mathrm{NaCl}$-induced $\left[\mathrm{Ca}^{2+}\right]_{\mathrm{i}}$ as well as the $\mathrm{NaCl}$-triggered overproduction of ROS possibly function as critical integrators, mediating stress signal perception, signal transduction, and adaptation (Xie et al., 2011; Ma et al., 2012; Jiang et al., 2013; Ben et al., 2015; Köster et al., 2018). The salt stress-induced $\left[\mathrm{Ca}^{2+}\right]_{\mathrm{i}}$ increases precede the production of $\mathrm{H}_{2} \mathrm{O}_{2}$ signaling molecule (Yang and Poovaiah, 2002). $\mathrm{NaCl}$ and $\mathrm{H}_{2} \mathrm{O}_{2}$ induce $\left[\mathrm{Ca}^{2+}\right]_{\mathrm{i}}$ increases and activate distinct $\mathrm{Ca}^{2+}$ permeable channels (Jiang et al., 2013), suggesting that calcium plays a central role in $\mathrm{NaCl}$ and $\mathrm{H}_{2} \mathrm{O}_{2}$ signal transduction pathways in plants.
Here we found that basal $\left[\mathrm{Ca}^{2+}\right]_{\mathrm{i}}$ decreased under salt and oxidative stress environments (Figure 1). Considering that the basal $\left[\mathrm{Ca}^{2+}\right]_{\mathrm{i}}$ levels are maintained at approximately $100 \mathrm{nM}$, the low basal $\left[\mathrm{Ca}^{2+}\right]_{\mathrm{i}}$ levels in plants grown in $\mathrm{NaCl}$ medium and $\mathrm{H}_{2} \mathrm{O}_{2}$ medium, seen in this study (Figure 1), indicates that the low levels may allow plants to adapt well to salt and oxidative environmental stresses. The $\mathrm{Ca}^{2+}$ sensor proteins with diverse $\mathrm{Ca}^{2+}$ affinities, subcellular localizations, and downstream target specificities perceive $\left[\mathrm{Ca}^{2+}\right]_{\mathrm{i}}$ changes and transduce them into downstream signaling responses (Hashimoto and Kudla, 2011). It seems essential for plants to maintain a lower basal $\left[\mathrm{Ca}^{2+}\right]_{\mathrm{i}}$ under stressed environmental conditions. It is possible that the $\mathrm{Ca}^{2+}$ sensors allow the plant to tightly control the appropriate adaptation to changes and provide a robust response to additional stimuli from the environment. The lower basal $\left[\mathrm{Ca}^{2+}\right]_{\mathrm{i}}$ can only activate high affinity $\mathrm{Ca}^{2+}$ sensors, and thus proportionally promote the high-affinity- $\mathrm{Ca}^{2+}$-sensor-mediated signaling pathways. It remains to be addressed why the basal $\left[\mathrm{Ca}^{2+}\right]_{\mathrm{i}}$ of the root is lowered more than that of the leaf in $\mathrm{NaCl}$ medium but the $\left[\mathrm{Ca}^{2+}\right]_{i}$ of the root and leaf is similar in $\mathrm{H}_{2} \mathrm{O}_{2}$ medium (Figures 1B,D). Roots grow in the salt stress soil environment, but the leaf is almost not directly contacted with the salt in the soil. Based on the previous research, the salt is absorbed from the site of application of the gel, which triggers the propagation of the $\mathrm{Ca}^{2+}$ wave and induction of systemic molecular responses in the leaf that are unlikely to reflect direct responses to salt stress (Choi et al., 2014). We consider the initial $\mathrm{Ca}^{2+}$ signatures as the main springboard to further research.

Through the application of different concentrations of stimuli to plants, the relationship between the strength of stimulus and magnitude of $\left[\mathrm{Ca}^{2+}\right]_{i}$ could be found. The magnitudes of $\left[\mathrm{Ca}^{2+}\right]_{\mathrm{i}}$ increases rely on the strength of stimulus, wherein, higher the strength applied the more considerable is the rise in $\left[\mathrm{Ca}^{2+}\right]_{\mathrm{i}}$, which is observed until the saturation point is reached (Figure 2), and this is consistent with previous reports (Tracy et al., 2008; Jiang et al., 2013). Therefore, the correlation between stimulus strengths and $\left[\mathrm{Ca}^{2+}\right]_{\mathrm{i}}$ magnitudes may be a common dose effect in plants. Analysis of the dose effect of $\mathrm{NaCl}$-induced $\left[\mathrm{Ca}^{2+}\right]_{\mathrm{i}}$ increases demonstrated that the $\left[\mathrm{Ca}^{2+}\right]_{\mathrm{i}}$ in response to $\mathrm{NaCl}$ in the root is dramatically stronger than that in the leaf, and the $\left[\mathrm{Ca}^{2+}\right]_{\mathrm{i}}$ magnitudes between root and leaf are further elevated when the seedlings are grown in the $\mathrm{NaCl}$ medium (Figures 2A-C), indicating a sensitization mechanism under the imposed experimental conditions. In contrast, in the presence and absence of $\mathrm{H}_{2} \mathrm{O}_{2}$ in the medium, no differences of the $\left[\mathrm{Ca}^{2+}\right]_{\mathrm{i}}$ were found between the roots and leaves in the dose effects of $\mathrm{H}_{2} \mathrm{O}_{2}$ in both normal environmental and oxidative conditions, which means that the root and the leaf are neither sensitized nor desensitized when the seedlings were grown in oxidative medium (Figures 2D-F).

We have investigated the spatiotemporal patterns of the $\mathrm{NaCl}$ and $\mathrm{H}_{2} \mathrm{O}_{2}$-induced $\left[\mathrm{Ca}^{2+}\right]_{\mathrm{i}}$ increases and demonstrated that both $\mathrm{NaCl}$ and $\mathrm{H}_{2} \mathrm{O}_{2}$ evoke a transient increase in $\left[\mathrm{Ca}^{2+}\right]_{\mathrm{i}}$ which then decays to a new resting level (Figures 3, 4), similar to those seen in previous studies (Knight et al., 1997; Rentel and Knight, 2004; Jiang et al., 2013). The $\left[\mathrm{Ca}^{2+}\right]_{\mathrm{i}}$ elevations in roots from seedlings grown under $40 \mathrm{mM} \mathrm{NaCl}$ medium were similar to those from 
control medium-grown seedlings after application of $\mathrm{H}_{2} \mathrm{O}_{2}$ and $\mathrm{NaCl}$ stimulus, respectively (Figure 3). However, the $\left[\mathrm{Ca}^{2+}\right]_{\mathrm{i}}$ elevations within the leaf, induced by both $\mathrm{H}_{2} \mathrm{O}_{2}$ and $\mathrm{NaCl}$, significantly declined in $\mathrm{NaCl}$ medium compared to control medium. Moreover, the $\left[\mathrm{Ca}^{2+}\right]_{i}$ elevations of leaf stimulated by $\mathrm{NaCl}$ reduced more than that stimulated by $\mathrm{H}_{2} \mathrm{O}_{2}$ (Figures $3 \mathbf{C , F}$ ). These results indicate that the sensitivity of leaf is reduced in salt environmental stress. It is most likely that the $\mathrm{NaCl}$ evoked $\mathrm{Ca}^{2+}$ signature within the leaf might be adapted to salt environmental conditions, but the $\mathrm{H}_{2} \mathrm{O}_{2}$-evoked $\mathrm{Ca}^{2+}$ signature within the leaf might be only partly adapted to salt environmental conditions. Furthermore, after application of $\mathrm{H}_{2} \mathrm{O}_{2}$ and $\mathrm{NaCl}$, respectively, the $\left[\mathrm{Ca}^{2+}\right]_{\mathrm{i}}$ elevations of roots in the $\mathrm{H}_{2} \mathrm{O}_{2}$ medium are similar to those in $\mathrm{NaCl}$ medium (Figure 4). However, the $\mathrm{H}_{2} \mathrm{O}_{2}$-induced $\left[\mathrm{Ca}^{2+}\right]_{\mathrm{i}}$ in leaves was similar to that in roots (Figures 4A,C) and the $\mathrm{NaCl}$-induced $\left[\mathrm{Ca}^{2+}\right]_{\mathrm{i}}$ in leaves has a marked decline in the $\mathrm{H}_{2} \mathrm{O}_{2}$ medium (Figure 4F). These results indicate that the $\mathrm{NaCl}$-evoked $\mathrm{Ca}^{2+}$ signatures within the leaf might partly adapt to oxidative environmental stress condition with significant desensitization, while both the root and the leaf that are stimulated by $\mathrm{H}_{2} \mathrm{O}_{2}$ under the oxidative environmental conditions can maintain the same sensitivity as in normal environmental conditions.

Our results suggest that the root is the primary sensing tissue to perceive salt stress, and is more sensitive to salt stress when the seedlings are grown in the salt environment. Previous studies have shown that plants have stronger reactions on pre-exposure to drought stress to reduce water loss from leaves (Ding et al., 2012). In addition, plants have long-term somatic memory in epigenome (Sani et al., 2013). With respect to $\left[\mathrm{Ca}^{2+}\right]_{\mathrm{i}}$ signaling, plants exhibit rapid hyperosmotic-induced $\mathrm{Ca}^{2+}$ responses on pre-exposure to osmotic stress, also called "osmo-sensory potentiation" (Stephan et al., 2016). We found similar potentiation phenomenon in salt stress in the root but desensitization in the leaf. However, the oxidative stresses are different from salt and osmotic stresses - no potentiation and desensitization were observed. It is possible that the mechanistic aspects of salt stress (ionic and osmotic stresses) are shared with osmotic stress. When plants suffer from salt stress, they have to maintain enough $\left[\mathrm{Ca}^{2+}\right]_{\mathrm{i}}$ to transduce the $\mathrm{Ca}^{2+}$ signatures to trigger the downstream events in the whole plants, but too much $\left[\mathrm{Ca}^{2+}\right]_{\mathrm{i}}$ can also become toxic. So we speculate that in the process of plants to adapt to salt stress, the basal $\left[\mathrm{Ca}^{2+}\right]_{i}$ decreases with pre-exposure to salt stress environment, leading to weaker $\mathrm{Ca}^{2+}$ signaling pathways. We have known that salt stress can trigger the SAA (Systemic acquired acclimation) (Gilroy et al., 2014), which enable whole plants to prepare all of their tissues and cells to an upcoming challenge, even though that may initially only be sensed by root tissues. It may indicate why the basal $\left[\mathrm{Ca}^{2+}\right]_{i}$ in the leaf are decreased for the future upcoming stimulates.

In comparison with plants that cope with salt stress, our data showed that in the process of plant adaption to ROS stress, they have a delicate ROS balance between their production and scavenging, in which ROS does not need to be stored in a particular compartment and could be rapidly generated and/or removed anywhere in the cell or the apoplast (Choi et al., 2014). We have established that the magnitude of salt stress-induced
$\left[\mathrm{Ca}^{2+}\right]_{\mathrm{i}}$ increases and the ROS-induced $\left[\mathrm{Ca}^{2+}\right]_{\mathrm{i}}$ increases are affected by both salt and oxidative environments. We also studied the relationship between salt- and ROS-induced $\left[\mathrm{Ca}^{2+}\right]_{\mathrm{i}}$ increases in leaves and roots, respectively. Our data suggest that previous studies on $\mathrm{NaCl}$ - and $\mathrm{H}_{2} \mathrm{O}_{2}$-induced $\left[\mathrm{Ca}^{2+}\right]_{\mathrm{i}}$ increases are much more complicated in leaf and root under the salt and oxidative environments (Knight et al., 1997; Rentel and Knight, 2004; Jiang et al., 2013). By imaging $\left[\mathrm{Ca}^{2+}\right]_{\mathrm{i}}$ changes, we found the basal $\left[\mathrm{Ca}^{2+}\right]_{\mathrm{i}}$ decrease was dependent on the saline and oxidative environments. Detailed image analyses and comparisons of the $\left[\mathrm{Ca}^{2+}\right]_{\mathrm{i}}$ increases suggest that the roots are more sensitive than the leaves in response to environmental stress conditions. The increases evoked by $\mathrm{NaCl}$ are different from those by $\mathrm{H}_{2} \mathrm{O}_{2}$ in salt and oxidative environmental stresses, respectively, indicating that there is a different mechanism in the plant evolution process in response to both long-term and transient stress.

\section{AUTHOR CONTRIBUTIONS}

ZJ and Z-MP designed the experiments. LL performed the research. LL, ZJ, SZ, HZ, and WY collected and analyzed the data. LL, ZJ, JS, and Z-MP wrote the manuscript. All authors discussed the results and contributed to the manuscript.

\section{FUNDING}

This work was supported by grants from Chinese NSF (NSFC31301170) to ZJ, Zhejiang NSF (LZ16C020001), NSF (IOS1457257), and DOE (DE-SC0014077).

\section{ACKNOWLEDGMENTS}

We thank Drs. Marc R. Knight for Arabidopsis seeds expressing aequorin, members in the Pei Lab for discussion and critical reading of the manuscript, and Douglas $\mathrm{M}$. Johnson and Gary B. Swift for the maintenance of the ChemiPro system.

\section{SUPPLEMENTARY MATERIAL}

The Supplementary Material for this article can be found online at: https://www.frontiersin.org/articles/10.3389/fpls.2018.01390/ full\#supplementary-material

FIGURE S1 | Long-term $\mathrm{H}_{2} \mathrm{O}_{2}$ and $\mathrm{NaCl}$ treatment alters relative genes expression. (A,B) Arabidopsis seedlings grown in MS media containing 0 or $1 \mathrm{mM}$ $\mathrm{H}_{2} \mathrm{O}_{2}$ and $40 \mathrm{mM} \mathrm{NaCl}$ for 10 days. We measured several salt stress relative gene markers such as SOS1, SOS2, SOS3, and TPC1 in leaf (A) and root (B). They are all up-regulated in root except TPC1, and they are all up-regulated in leaf. Similar results were seen in four independent experiments using 40 seedlings. (C,D) Similarly, we measured ROS stress relative gene markers such as ZAT12, RBOHD, and TPC1 in root and leaf. The ZAT12 and RBOHD are all up-regulated both in leaf (C) and root (D), but the TPC1 relative expression is down-regulated both in leaf (C) and root (D). Similar results were seen in four independent experiments using 40 seedlings.

TABLE S1 | Marker Gene Primer. 


\section{REFERENCES}

Ben, R. K., Lefebvre-De, V. D., Le, D. I., Leprince, A. S., Bordenave, M., Maldiney, R., et al. (2015). Hydrogen peroxide produced by NADPH oxidases increases proline accumulation during salt or mannitol stress in Arabidopsis thaliana. New Phytol. 208, 1138-1148. doi: 10.1111/nph.13550

Ben Rejeb, K., Abdelly, C., and Savoure, A. (2014). How reactive oxygen species and proline face stress together. Plant Physiol. Biochem. 80, 278-284. doi: 10.1016/j. plaphy.2014.04.007

Berridge, M. J., Bootman, M. D., and Roderick, H. L. (2003). Calcium signalling: dynamics, homeostasis and remodelling. Nat. Rev. Mol. Cell Biol. 4, 517-529. doi: $10.1038 / \mathrm{nrm} 1155$

Borsani, O., Zhu, J. H., Verslues, P. E., Sunkar, R., and Zhu, J. K. (2005). Endogenous siRNAs derived from a pair of natural cis-antisense transcripts regulate salt tolerance in Arabidopsis. Cell 123, 1279-1291. doi: 10.1016/j.cell. 2005.11.035

Bose, J., Rodrigomoreno, A., Lai, D., Xie, Y., Shen, W., and Shabala, S. (2015). Rapid regulation of the plasma membrane $\mathrm{H}^{+}$-ATPase activity is essential to salinity tolerance in two halophyte species, Atriplex lentiformis and Chenopodium quinoa. Ann. Bot. 115, 481-494. doi: 10.1093/aob/mcu219

Cao, X. Q., Jiang, Z. H., Yi, Y. Y., Yang, Y., Ke, L. P., Pei, Z. M., et al. (2017). Biotic and abiotic stresses activate different $\mathrm{Ca}^{2+}$ permeable channels in Arabidopsis. Front. Plant Sci. 8:83. doi: 10.3389/Fpls.2017.00083

Choi, W. G., Hilleary, R., Swanson, S. J., Kim, S. H., and Gilroy, S. (2016). Rapid, long-distance electrical and calcium signaling in plants. Annu. Rev. Plant Biol. 67, 287-307. doi: 10.1146/annurev-arplant-043015-112130

Choi, W. G., Toyota, M., Kim, S. H., Hilleary, R., and Gilroy, S. (2014). Salt stress-induced $\mathrm{Ca}^{2+}$ waves are associated with rapid, long-distance rootto-shoot signaling in plants. Proc. Natl. Acad. Sci. U.S.A. 111, 6497-6502. doi: $10.1073 /$ pnas.1319955111

Clapham, D. E. (2007). Calcium signaling. Cell 131, 1047-1058. doi: 10.1016/j.cell. 2007.11.028

Deinlein, U., Stephan, A. B., Horie, T., Luo, W., Xu, G., and Schroeder, J. I. (2014). Plant salt-tolerance mechanisms. Trends Plant Sci. 19, 371-379. doi: 10.1016/j.tplants.2014.02.001

Ding, Y., Fromm, M., and Avramova, Z. (2012). Multiple exposures to drought 'train' transcriptional responses in Arabidopsis. Nat. Commun. 3:740. doi: $10.1038 /$ ncomms 1732

Dodd, A. N., Kudla, J., and Sanders, D. (2010). The language of calcium signaling. Annu. Rev. Plant Biol. 61, 593-620. doi: 10.1146/annurev-arplant-070109104628

Epstein, E. (1961). The essential role of calcium in selective cation transport by plant cells. Plant Physiol. 36, 437-444. doi: 10.1104/pp.36.4.437

Evans, M. J., Choi, W. G., Gilroy, S., and Morris, R. J. (2016). A ROS-assisted calcium wave dependent on the AtRBOHD NADPH oxidase and TPC1 cation channel propagates the systemic response to salt stress. Plant Physiol. 171, 1771. doi: 10.1104/pp.16.00215

Gilroy, S., Suzuki, N., Miller, G., Choi, W. G., Toyota, M., Devireddy, A. R., et al. (2014). A tidal wave of signals: calcium and ROS at the forefront of rapid systemic signaling. Trends Plant Sci. 19, 623-630. doi: 10.1016/j.tplants.2014. 06.013

Guo, J., Zeng, W., and Jiang, Y. (2017). Tuning the ion selectivity of two-pore channels. Proc. Natl. Acad. Sci. U.S.A. 114, 1009-1014. doi: 10.1073/pnas. 1616191114

Harper, J. F., and Harmon, A. (2005). Plants, symbiosis and parasites: a calcium signalling connection. Nat. Rev. Mol. Cell Biol. 6, 555-566. doi: 10.1038/ nrm 1679

Hasegawa, P. M., Bressan, R. A., Zhu, J. K., and Bohnert, H. J. (2000). Plant cellular and molecular responses to high salinity. Ann. Rev. Plant Physiol. Plant Mol. Biol. 51, 463-499. doi: 10.1146/annurev.arplant.51.1.463

Hashimoto, K., and Kudla, J. (2011). Calcium decoding mechanisms in plants. Biochimie 93, 2054-2059. doi: 10.1016/j.biochi.2011. 05.019

Hepler, P. K. (2005). Calcium: a central regulator of plant growth and development. Plant Cell 17, 2142-2155. doi: 10.1105/tpc.105.032508

Hetherington, A. M., and Brownlee, C. (2004). The generation of $\mathrm{Ca}^{2+}$ signals in plants. Annu. Rev. Plant Biol. 55, 401-427. doi: 10.1146/annurev.arplant.55. 031903.141624
Hofer, A. M., and Brown, E. M. (2003). Extracellular calcium sensing and signalling. Nat. Rev. Mol. Cell Biol. 4, 530-538. doi: 10.1038/nrm1154

Jiang, Z. H., Zhu, S., Ye, R., Xue, Y., Chen, A., An, L. Z., et al. (2013). Relationship between NaCl- and $\mathrm{H}_{2} \mathrm{O}_{2}$-induced cytosolic $\mathrm{Ca}^{2+}$ increases in response to stress in Arabidopsis. PLoS One 8:e76130. doi: 10.1371/journal.pone.0076130

Johnson, C. H., Knight, M. R., Kondo, T., Masson, P., Sedbrook, J., Haley, A., et al. (1995). Circadian oscillations of cytosolic and chloroplastic free calcium in plants. Science 269, 1863-1865. doi: 10.1126/science.7569925

Kaya, H., Nakajima, R., Iwano, M., Kanaoka, M. M., Kimura, S., Takeda, S., et al. (2014). $\mathrm{Ca}^{2+}$-activated reactive oxygen species production by Arabidopsis $\mathrm{RbohH}$ and $\mathrm{RbohJ}$ is essential for proper pollen tube tip growth. Plant Cell 26, 1069-1080. doi: 10.1105/tpc.113.120642

Kiep, V., Vadassery, J., Lattke, J., Maass, J. P., Boland, W., Peiter, E., et al. (2015). Systemic cytosolic $\mathrm{Ca}^{2+}$ elevation is activated upon wounding and herbivory in Arabidopsis. New Phytol. 207, 996-1004. doi: 10.1111/nph.13493

Knight, H., and Knight, M. R. (2001). Abiotic stress signalling pathways: specificity and cross-talk. Trends Plant Sci. 6, 262-267. doi: 10.1016/s1360-1385(01) 01946-x

Knight, H., Trewavas, A. J., and Knight, M. R. (1997). Calcium signalling in Arabidopsis thaliana responding to drought and salinity. Plant J. 12, 1067-1078. doi: 10.1046/j.1365-313X.1997.12051067.x

Knight, M. R., Campbell, A. K., Smith, S. M., and Trewavas, A. J. (1991). Transgenic plant aequorin reports the effects of touch and cold-shock and elicitors on cytoplasmic calcium. Nature 352, 524-526. doi: 10.1038/352524a0

Köster, P., Wallrad, L., Edel, K. H., Faisal, M., Alatar, A. A., and Kudla, J. (2018). The battle of two ions: $\mathrm{Ca}^{2+}$ signalling against $\mathrm{Na}^{+}$stress. Plant Biol. doi: 10.1111/plb.12704 [Epub ahead of print].

Kurusu, T., Kuchitsu, K., and Tada, Y. (2015). Plant signaling networks involving $\mathrm{Ca}^{2+}$ and Rboh/Nox-mediated ROS production under salinity stress. Front. Plant Sci. 6:427. doi: 10.3389/fpls.2015.00427

Leshem, Y., Seri, L., and Levine, A. (2007). Induction of phosphatidylinositol 3kinase-mediated endocytosis by salt stress leads to intracellular production of reactive oxygen species and salt tolerance. Plant J. 51, 185-197. doi: 10.1111/j. 1365-313X.2007.03134.x

Ma, L., Zhang, H., Sun, L., Jiao, Y., Zhang, G., Miao, C., et al. (2012). NADPH oxidase AtrbohD and AtrbohF function in ROS-dependent regulation of $\mathrm{Na}^{+} / \mathrm{K}^{+}$homeostasis in Arabidopsis under salt stress. J. Exp. Bot. 63, 305-317. doi: $10.1093 /$ jxb/err280

Ma, W., and Berkowitz, G. A. (2011). Ca2( conduction by plant cyclic nucleotide gated channels and associated signaling components in pathogen defense signal transduction cascades. New Phytol. 190, 566-572. doi: 10.1111/j.1469-8137. 2010.03577.x

Marti, M. C., Stancombe, M. A., and Webb, A. A. (2013). Cell- and stimulus type-specific intracellular free $\mathrm{Ca}^{2+}$ signals in Arabidopsis. Plant Physiol. 163, 625-634. doi: 10.1104/pp.113.222901

McAinsh, M. R., Clayton, H., Mansfield, T. A., and Hetherington, A. M. (1996). Changes in stomatal behavior and guard cell cytosolic free calcium in response to oxidative stress. Plant Physiol. 111, 1031-1042. doi: 10.1104/pp.111.4.103

McAinsh, M. R., and Pittman, J. K. (2009). Shaping the calcium signature. New Phytol. 181, 275-294. doi: 10.1111/j.1469-8137.2008.02682.x

Miller, G., Suzuki, N., Ciftci-Yilmaz, S., and Mittler, R. (2010). Reactive oxygen species homeostasis and signalling during drought and salinity stresses. Plant Cell Environ. 33, 453-467. doi: 10.1111/j.1365-3040.2009.02041.x

Mittler, R. (2002). Oxidative stress, antioxidants and stress tolerance. Trends Plant Sci. 7, 405-410. doi: 10.1016/S1360-1385(02)02312-9

Munns, R., and Tester, M. (2008). Mechanisms of salinity tolerance. Annu. Rev. Plant Biol. 59, 651-681. doi: 10.1146/annurev.arplant.59.032607.092911

Pei, Z.-M., Murata, Y., Benning, G., Thomine, S., Klusener, B., Allen, G. J., et al. (2000). Calcium channels activated by hydrogen peroxide mediate abscisic acid signalling in guard cells. Nature 406, 731-734. doi: 10.1038/35021067

Ranf, S., Gisch, N., Schaffer, M., Illig, T., Westphal, L., Knirel, Y. A., et al. (2015). A lectin S-domain receptor kinase mediates lipopolysaccharide sensing in Arabidopsis thaliana. Nat. Immunol. 16, 426-433. doi: 10.1038/ni.3124

Rentel, M. C., and Knight, M. R. (2004). Oxidative stress-induced calcium signaling in Arabidopsis. Plant Physiol. 135, 1471-1479. doi: 10.1104/pp.104.042663

Roderick, H. L., and Cook, S. J. (2008). $\mathrm{Ca}^{2+}$ signalling checkpoints in cancer: remodelling $\mathrm{Ca}^{2+}$ for cancer cell proliferation and survival. Nat. Rev. Cancer 8, 361-375. doi: 10.1038/nrc2374 
Ru, Q. M., Pei, Z. M., and Zheng, H. L. (2008). In vitro studies on antioxidant and antimicrobial activities of polysaccharide from Lycoris aurea. Zhong Yao Cai 31, 1536-1540.

Sammels, E., Parys, J. B., Missiaen, L., De Smedt, H., and Bultynck, G. (2010). Intracellular $\mathrm{Ca}^{2+}$ storage in health and disease: a dynamic equilibrium. Cell Calcium 47, 297-314. doi: 10.1016/j.ceca.2010.02.001

Sani, E., Herzyk, P., Perrella, G., Colot, V., and Amtmann, A. (2013). Hyperosmotic priming of Arabidopsis seedlings establishes a long-term somatic memory accompanied by specific changes of the epigenome. Genome Biol. 14:R59. doi: 10.1186/gb-2013-14-6-r59

Schroeder, J. I., Delhaize, E., Frommer, W. B., Guerinot, M. L., Harrison, M. J. Herrera-Estrella, L., et al. (2013). Using membrane transporters to improve crops for sustainable food production. Nature 497, 60-66. doi: 10.1038/ nature 11909

Stephan, A. B., Kunz, H. H., Yang, E., and Schroeder, J. I. (2016). Rapid hyperosmotic-induced $\mathrm{Ca}^{2+}$ responses in Arabidopsis thaliana exhibit sensory potentiation and involvement of plastidial KEA transporters. Proc. Natl. Acad. Sci. U.S.A. 113, E5242. doi: 10.1073/pnas.1519555113

Suzuki, N., Koussevitzky, S., Mittler, R., and Miller, G. (2012). ROS and redox signalling in the response of plants to abiotic stress. Plant Cell Environ. 35, 259-270. doi: 10.1111/j.1365-3040.2011.02336.x

Swanson, S. J., Choi, W. G., Chanoca, A., and Gilroy, S. (2011). In vivo imaging of $\mathrm{Ca}^{2+}, \mathrm{pH}$, and reactive oxygen species using fluorescent probes in plants. Annu. Rev. Plant Biol. 62, 273-297. doi: 10.1146/annurev-arplant-042110- 103832

Tang, R. H., Han, S., Zheng, H., Cook, C. W., Choi, C. S., Woerner, T. E., et al. (2007). Coupling diurnal cytosolic $\mathrm{Ca}^{2+}$ oscillations to the CAS-IP3 pathway in Arabidopsis. Science 315, 1423-1426. doi: 10.1126/science.1134457

Tracy, F. E., Gilliham, M., Dodd, A. N., Webb, A. A., and Tester, M. (2008). $\mathrm{NaCl}$-induced changes in cytosolic free $\mathrm{Ca}^{2+}$ in Arabidopsis thaliana are heterogeneous and modified by external ionic composition. Plant Cell Environ. 31, 1063-1073. doi: 10.1111/j.1365-3040.2008.01817.x

Vaidyanathan, H., Sivakumar, P., Chakrabarty, R., and Thomas, G. (2003). Scavenging of reactive oxygen species in $\mathrm{NaCl}$-stressed rice (Oryza sativa L.) - differential response in salt-tolerant and sensitive varieties. Plant Sci. 165, 1411-1418. doi: 10.1016/j.plantsci.2003.08.005

Valderrama, R., Corpas, F. J., Carreras, A., Gomez-Rodriguez, M. V., Chaki, M., Pedrajas, J. R., et al. (2006). The dehydrogenase-mediated recycling of NADPH is a key antioxidant system against salt-induced oxidative stress in olive plants. Plant Cell Environ. 29, 1449-1459. doi: 10.1111/j.1365-3040.2006.01530.x

Vranova, E., Inze, D., and Van Breusegem, F. (2002). Signal transduction during oxidative stress. J. Exp. Bot. 53, 1227-1236. doi: 10.1093/jexbot/53.372.1227
Ward, J. M., Maser, P., and Schroeder, J. I. (2009). Plant ion channels: gene families, physiology, and functional genomics analyses. Annu. Rev. Physiol. 71, 59-82. doi: 10.1146/annurev.physiol.010908.163204

Waring, P. (2005). Redox active calcium ion channels and cell death. Arch. Biochem. Biophys. 434, 33-42. doi: 10.1016/j.abb.2004.08.001

Wise, R. R., and Naylor, A. W. (1987). Chilling-enhanced photooxidation: the peroxidative destruction of lipids during chilling injury to photosynthesis and ultrastructure. Plant Physiol. 83, 272-277. doi: 10.1104/pp.83.2.272

Xie, Y. J., Xu, S., Han, B., Wu, M. Z., Yuan, X. X., Han, Y., et al. (2011). Evidence of Arabidopsis salt acclimation induced by up-regulation of HY1 and the regulatory role of RbohD-derived reactive oxygen species synthesis. Plant J. Cell Mol. Biol. 66, 280-292. doi: 10.1111/j.1365-313X.2011.04488.x

Yang, T., and Poovaiah, B. W. (2002). Hydrogen peroxide homeostasis: activation of plant catalase by calcium/calmodulin. Proc. Natl. Acad. Sci. U.S.A. 99, 4097-4102. doi: 10.1073/pnas.052564899

Yuan, F., Yang, H., Xue, Y., Kong, D., Ye, R., Li, C., et al. (2014). OSCA1 mediates osmotic-stress-evoked $\mathrm{Ca}^{2+}$ increases vital for osmosensing in Arabidopsis. Nature 514, 367-371. doi: 10.1038/nature13593

Zhu, J. K. (2001). Plant salt tolerance. Trends Plant Sci. 6, 66-71. doi: 10.1016/ S1360-1385(00)01838-0

Zhu, J. K. (2002). Salt and drought stress signal transduction in plants. Annu. Rev. Plant Biol. 53, 247-273. doi: 10.1146/annurev.arplant.53.091401.143329

Zhu, J. K. (2003). Regulation of ion homeostasis under salt stress. Curr. Opin. Plant Biol. 6, 441-445. doi: 10.1016/S1369-5266(03)00085-2

Zhu, J. K. (2016). Abiotic stress signaling and responses in plants. Cell 167, 313-324. doi: 10.1016/j.cell.2016.08.029

Zhu, S., Zhou, X. P., Wu, X. M., and Jiang, Z. H. (2013). Structure and function of the CBL-CIPK $\mathrm{Ca}^{2+}$-decoding system in plant calcium signaling. Plant Mol. Biol. Report. 31, 1193-1202. doi: 10.1007/s11105-013-0631-y

Conflict of Interest Statement: The authors declare that the research was conducted in the absence of any commercial or financial relationships that could be construed as a potential conflict of interest.

Copyright (c) 2018 Liu, Jiang, Zhang, Zhao, Yang, Siedow and Pei. This is an openaccess article distributed under the terms of the Creative Commons Attribution License (CC BY). The use, distribution or reproduction in other forums is permitted, provided the original author(s) and the copyright owner(s) are credited and that the original publication in this journal is cited, in accordance with accepted academic practice. No use, distribution or reproduction is permitted which does not comply with these terms. 